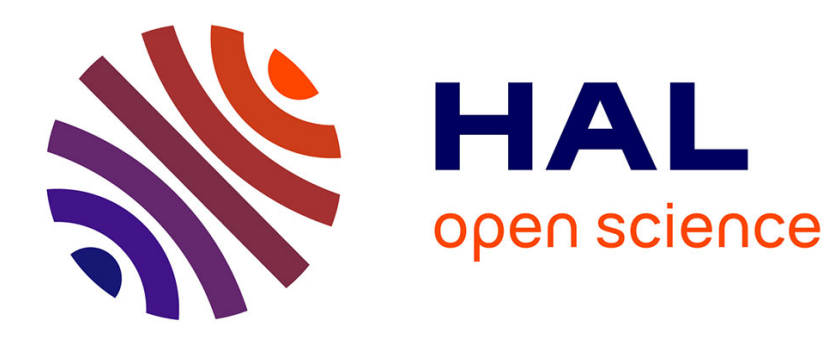

\title{
From Shusterman's Somaesthetics to a Radical Epistemology of Somatics
}

Isabelle Ginot

\section{To cite this version:}

Isabelle Ginot. From Shusterman's Somaesthetics to a Radical Epistemology of Somatics. Dance Research Journal, 2010, Summer ( $\left.{ }^{\circ} 42\right)$, p. 12-29. hal-02293708

HAL Id: hal-02293708

https://hal-univ-paris8.archives-ouvertes.fr/hal-02293708

Submitted on 25 Oct 2019

HAL is a multi-disciplinary open access archive for the deposit and dissemination of scientific research documents, whether they are published or not. The documents may come from teaching and research institutions in France or abroad, or from public or private research centers.
L'archive ouverte pluridisciplinaire HAL, est destinée au dépôt et à la diffusion de documents scientifiques de niveau recherche, publiés ou non, émanant des établissements d'enseignement et de recherche français ou étrangers, des laboratoires publics ou privés. 


\section{FROM}

Isabelle GINOT

\section{SHUSTER}
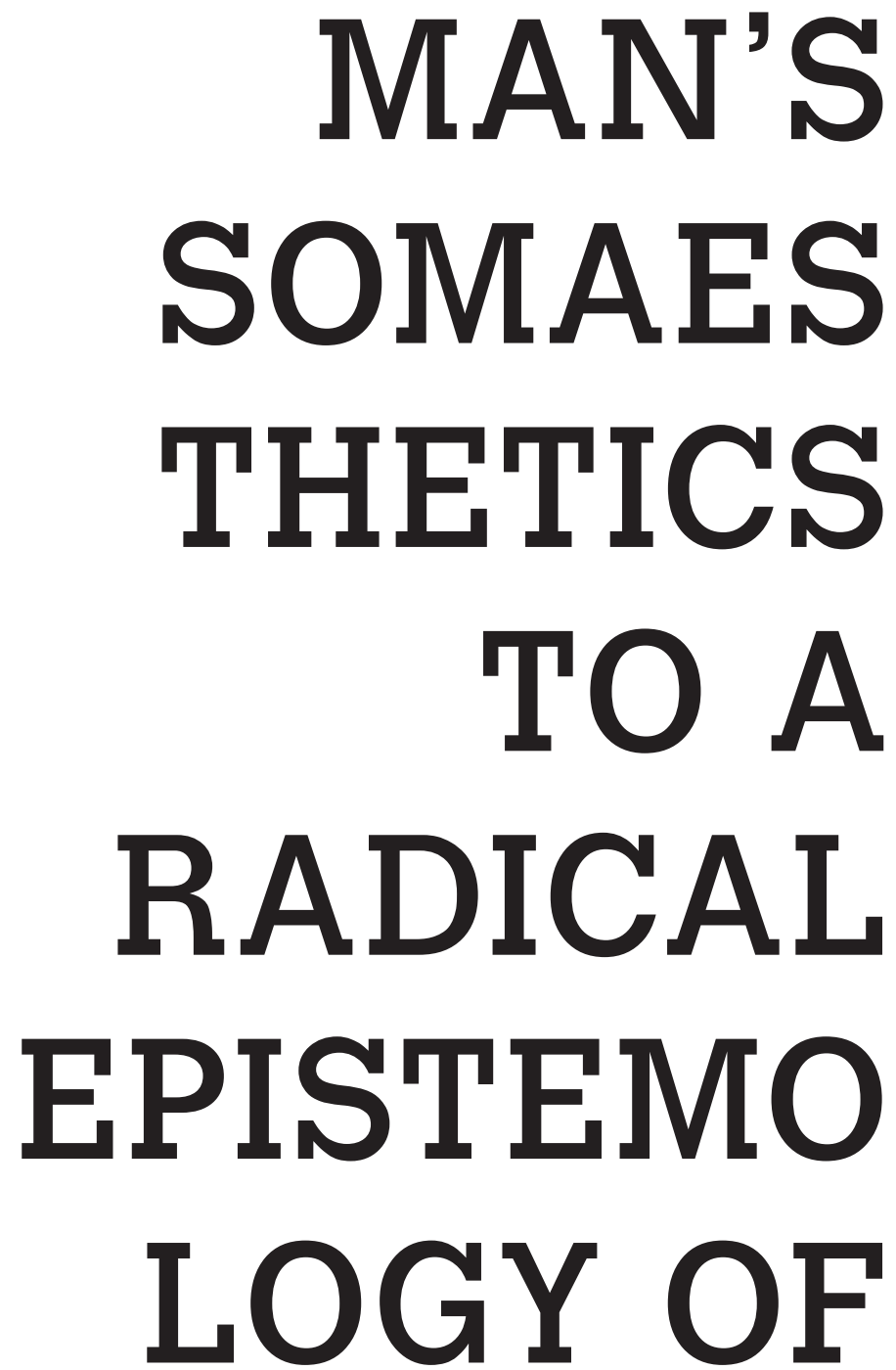

$10 \begin{aligned} & \text { in Dance research journal, } \mathrm{n}^{\circ} 42, \text { Univer- } \\ & \text { sity of Illinois Press, Champaign (USA), } \\ & \text { été } 2010, \mathrm{p} .12-29\end{aligned}$ 


\title{
From Shusterman's Somaesthetics to a Radical Epistemology of Somatics
}

\author{
Isabelle Ginot
}

$\mathrm{F}$ rom the precepts of civility and physical deportment in the early modern era to modern gestural routines found in physical therapy and gymnastics, cultural historians of the body have studied the physical practices of hygiene, sports, and medicine. ${ }^{1}$ The history of dance is marked by these dance-related practices, which are peripheral to dance itself. One set of contemporary peripheral practices sought out by dancers themselves has been called "somatics," a term Thomas Hanna proposed in the r970s (I995). Somatics has since made its way into the dance world, where by now it has achieved widespread recognition as a form of bodily knowledge. This article is concerned with the epistemological status of somatics and, therefore, with the discursive production characteristic of its methods and practices.

The first value that we usually attribute to these practices is prophylactic: they serve to prevent professional accidents or provide functional rehabilitation following injuries. Although increasingly integrated into dancer training and dance pedagogy, somatics first found its way into dance as a means to limit accidents. Somatics is also often a resource for the improvement of virtuosity in dance. But it has nevertheless transformed pedagogy into a more "active" and exploratory experience for the student, in which physical sensations are more important than the mirroring and reproduction of forms (Fortin 1996, 2005; Fortin, Long, and Lord 2002). We often see it presented as a "counter power," an antidote to dominant dance practices. This point of view is poorly documented - possibly because it would not hold up against a strong argument - but it is common knowledge that somatics stands opposed to virtuosity and the "perfect" body image, as seen, for example, in the role these techniques played in the early part of Trisha Brown's choreographic career. ${ }^{3}$ Somatics can thus be considered a conceptual

Isabelle Ginot is professor of dance at the University of Paris 8 (Saint Denis-Vincennes) and a Feldenkrais practitioner. Her research in contemporary dance emphasizes issues of perception and has led her to inquire into the practices of dancers. The epistemology of somatics as well as its use in dance and medicine are the focus of her current research. She is director of a university degree program in "Techniques of the Body and the World of Medical Care" and is developing new physical practices for persons living with HIV/AIDS. She has published Dominique Bagouet, un labyrinthe dansé (Pantin: Centre National de la Danse, 1999) and is currently preparing a second book: La critique en danse contemporaine: théries et pratiques, pertinences et délires. 
apparatus that enhances our understanding of pedagogy, dancer's health, and corporeal and gestural aesthetics.

Dance studies has begun to approach these practices and to define them as objects of research by privileging two axes: (I) documentation and evidence; and (2) efficacy, particularly in the pedagogical domain. ${ }^{4}$ The point of view I will grapple with here, however, is of a different nature. Rather than considering the question of the pedagogical, preventive, or aesthetic efficacy of somatics for dance, I want to examine the epistemological status of somatics. How is the bodily knowledge of somatics elaborated and circulated? Somatics, after all, presents itself as an empirically based mode of bodily thinking whose discourse relies strongly on oral tradition.

\section{Somatic Discourses}

Somatics, much like almost everything associated with practices of the body, suffers from undertheorization, and it is not entirely free from a tenacious doxa that physical sensations must irrevocably elude language. Undertheorization, however, does not entail the absence of language or discourse. On the contrary, the necessities of publicity, teaching, and exchange amongst practitioners are sites of intense discursive production. I will use the word "endogenous" to refer to these discourses of the professional world. Let us consider three main spheres where endogenous somatic discourse is produced:

- At the sites of therapeutic practice aimed at students, patients, and the general public the discourse is oral. However, there is also a written element, found in promotional texts for recruiting clientele.

- At the sites of practitioner and teacher training we find a crucial if not principal resource for our study of the epistemological status of somatics. Knowledge is developed and transmitted in schools, workshops, introductory training courses, continuing education programs, and professional conferences. Transmitting knowledge is inseparable from imparting the ethics of the profession, its beliefs and explicative models, as well as its objective training methods. This knowledge is also predominantly oral, although not all methods and training centers are consistent with each other: certain methods generate written documents reserved for active or training practitioners.

- Finally, of course, there are published texts: notably those of the method's founders, as well as numerous reviews and professional publications whose standards, genres, and distribution vary from one method and country to another. ${ }^{5}$

I will not undertake here an exhaustive linguistic description of these discourses, but I will point out two prevalent yet antithetical ways of framing them. The first is a scientific discourse, and the second is a first-person narrative of recovery. The legitimation of these practices is at stake in each, and hence proof is a major concern because one must always be aware of and fend off suspicions or charlatanism by demonstrating the seriousness, hard work, and "verifiability" of the method.

\section{Proof by science}

Let us examine the way somatics puts scientific discourse to use. Somatics focuses on physical sensation and the fundamentally unique experience of each person, but it needs 
to affirm its value in accordance with society's belief in the objective truth of science. To my knowledge, no single "modern" somatic method exists that fails to make this connection between subjective experience and objective proof. This connection appears in sometimes incongruous forms that often get superimposed within one discourse or a series of discourses.

Consider the importance of the authority figure. In many works by the "founders," we find prefaces, afterwords, tributes, and acknowledgements whose various authors, supposedly of a certain prestige, are singled out from among other men of science. Even Alexander who, as Michel Bernard (20oI) has pointed out, has no scientific credentials, is given John Dewey's scientific seal of approval in that the latter's philosophical credentials serve to affirm how Alexander's research methodology satisfies the tests of science ${ }^{6}$ :

Speaking as a pupil, it was because of this fact as demonstrated in personal experience that I first became convinced of the scientific quality of Mr. Alexander's work. Each lesson was a laboratory experimental demonstration ... In re-affirming my conviction as to the scientific character of Mr. Alexander's discoveries and technique, I do so then not as one who has experienced a "cure," but as one who has brought whatever intellectual capacity to the things which I had "known"in the sense of theoretical belief-in philosophy and psychology, changed into vital experiences which gave a new meaning to knowledge of them." (Dewey in Alexander 1932, xvi-xviii)

At the end of the same book, Alexander presents various "cases" for which doctors asked his help. A letter of support of his position in one case, signed by no less than seven doctors, is published in an appendix! Bonnie Bainbridge Cohen, for her part, cites her "inspirations" at length and devotes several pages of homage to her "professors."

Consigned to the textual margins of preambles, introductions, prefaces, and appendices, these testimonies lend legitimacy to the main text without undermining its endogenous source: for any new knowledge to exist it must derive from the founder and his/her intellect, sometimes from his/her imposing cultural baggage (Feldenkrais, Cohen) or from some earlier genius to whom s/he is indebted (Elsa Gindler for Lily Ehrenfried and Charlotte Selver). ${ }^{8}$ As we will see, the other characteristic of the somatic discourse is to take itself as true because it emanates from a singular, lived experience. Coordinating these two warrants is far from automatic, with the result that the scientific (exogenous) discourse remains at the margins of the founder's central text. Science thus functions like a validating gaze cast over somatics from afar. Nevertheless, scientists willingly endorse the legitimacy of endogenous somatic methods because they are assumed to go where science does not tread.

Yet somatic discourse still requires the framework of scientific knowledge. The Feldenkrais Method, for example, places somatics in the grand scheme of the evolution of species. ${ }^{9}$ All of Feldenkrais's writings-with the single exception of The Elusive Obvious (198I) - begin with a discussion of the evolution of species, even if Darwin himself is never mentioned by name. And evolutionary theory is one of the prominent models found in 
several other somatic systems. In Cohen's Body-Mind Centering (BMC), for example, the theory of the progressive acquisition of basic motor patterns in the young child is directly related to the history of cross-species evolution. Such a connection between onto- and phylo-genesis appears in numerous methods, most notably in the Feldenkrais Method. ${ }^{10}$ Evolution thus provides the ultimate legitimation: it gives a universal, even cosmic and a-historic, dimension to somatics, implying that all humans operate according to the same patterns. Does not somatics, by placing itself on the same plane as evolutionary theory, thus effectively situate itself on a suprahuman scale-beyond the reach of history and politics-paradoxically disengaged from all contingencies? ${ }^{11}$

The importance of scientific discourse, however, does not necessarily require direct recourse to these references. Even when the author is clearly informed of current scientific developments-in the Feldenkrais Method, for instance, debates on perception and lateralization-and the research shows strong signs of hesitation, and of proceeding by hypothesis/verification, science in somatic discourse represents a form of homogeneous, nonhistoricized, almost eternal truth. In sum, the scientific discourse used in somatic practices is not necessarily a guarantee of the scientific value of the work engaged in, and even less so of the potentially scientific attitude of its author. The function of science is neither to introduce doubt, nor to situate somatics within current scientific debates. Somatics does not depend on traditional scientific procedure that would require the description of experiments, the determination of the limits of validity of an argument, or the possible presentation of contradictory hypotheses. The function of science within somatics is to foster belief. Whereas somatic practice incessantly exposes differences in and the immaterial and elusive nature of sensing, scientific discourse inscribes vertiginous individual experience into a larger scheme whose uniformity promotes generalization. Somatics induces us to believe in the "scientific," universal, and "provable" nature of experience, in order to provide a stable collective context for what is fundamentally an unstable, highly individualized experience.

\section{Proof by experience: Injury, case study, examples}

The second major discursive trait of somatics is to highlight the value of individual experience over and above general experience. Here, the long succession of failures, and, finally, the persistence and tenacity of research legitimizes the founder's enterprise. Alexander's autobiography, The Use of the Self (1932), starts with his "founding injury" to culminate with various cases solved by his technique as developed through the long process of his own research, failures, and limits. ${ }^{12}$ The autobiographical genre, in both written and oral forms, informs numerous methods: Alexander's voice, Elsa Gindler's sickly constitution, Feldenkrais's knee, Gerda Alexander's rheumatisms - the list goes on. Here, legitimization is supposed to come not only from the positive solution of the narrative (the founder healed him or herself, then applied his/her "method" to others to heal them as well) but also from the founder's subjective engagement "in the flesh." The value of the method can be measured in part against the extent of the difficulties encountered: so, for example, Alexander does not hesitate to call attention to his own errors, bad habits, and misunder- 
standings, which are sustained by the general misunderstanding of his medical milieu, while Feldenkrais admits "For fear of ridicule I spoke to nobody, and remained unsure of what had happened. I was convinced there was something mentally wrong with me" $(\mathrm{I} 98 \mathrm{I}, 45)$. The value of the method can be measured in one sense by the extent of the gap between the beginning of the story (the gravity of the case presented), and the end of the same story (the successful healing). Finally, it can be measured by the degree of failure that others met with (doctors) on the same case. Another variety of story is that of the disciple, who combines personal experience (how I became the student of a master) and the glorification of the teaching received (Cabiers de l'association 1991).

Another genre of experiential narrative is the case study; this time, the central character is the student (or patient), who often takes on the role of victim. The intensity of his drama serves to measure the heroism of the practitioner-narrator, who resolves, or at least drastically reduces, the affliction that everyone was formerly unable to assuage. A good example is to be found in The Case of Nora (r977), where Feldenkrais tells the story from beginning to end of the treatment of a student who came to him after a cerebrovascular accident. He recounts the difficulties encountered and, most importantly, his strategies for resolving them. But the central character can also be an antihero steeped in aberrant representations and lamentable postures, whose certitudes regarding his/her own troubles reflect the incompetence and the misinterpretations of earlier practitioners, most often doctors or parents, who have brought him/her to where s/he is now. The narrator, then, appears to be the one whose knowledge, resisting the dominant interpretation, is solely capable of getting to the bottom of these prejudicial errors.

The case study enjoys a privileged place in the secondary literature, probably both because it complements the founder's discourse and because it belongs to scientific, medical, and psychoanalytical rhetoric (Sacks 2006). In the case study, the questing narrative voice fades away before the efficacy of the method. Having fewer difficulties means fewer partial failures, but more so, it signifies a well-oiled machine (the technique perfectly mastered by the practitioner) that responds without hesitation to the difficulties or demands of the student or patient. If these case studies generally aim to be conscious and considerate of the whole person (the criterion of all somatic methods), they rarely expose the practitioner's technique to scrutiny (Johnson 1997). What is the role of touch? How do the practitioner's actions embody his thinking? In this respect, also, these case studies, although they do reflect the practitioner's thinking, appeal to belief because they fail to account for experience, and thus they exclude, by that very fact, any possible doubt of or opposition to the result or its explanation.

The third genre of experiential narrative is what we shall call the exemplum. Whether true or invented, exempla enliven both oral and written discourse. The Feldenkrais Method, very prone to storytelling, makes abundant use of the exemplum, particularly in situations of teaching the general public or in training practitioners. Exempla can be chosen from among various extreme situations; one must therefore experience a sort of "miracle," a miracle that one must from that point on explain, demonstrating the rationality of the experience and re-enforcing the power of the method. But-and particularly when one addresses a nonspecialized public — we tend to prefer rather quotidian examples that, 
despite their individual character ("this is the story of someone who ...") resonate with more than one person. Such is the case with the canonical situation of Feldenkrais: if the loss of rotation in the spine is an abstract concept for most people, then the more concrete example of a student who has always avoided parallel parking his/her car because s/he couldn't turn around enough to look behind him/her would exemplify for everyone the benefits of a session on said rotation of the spine. Although they are often short and reduced to a rather schematic state, these stories follow the same rules as the first two kinds detailed above: one must always record the story of a person who has encountered an insoluble difficulty and who, thanks to the intervention of a practitioner and his/her technique, has resolved this difficulty. A perfect narrative model is in a way like a fairy tale that always has a happy ending and is laden with a moral significance that can be interpreted within the story itself.

The case study and the exemplum, therefore, seem to be key figures in the transmission of somatic knowledge. Most often, they are created to relay an experience the audience can relate to. They therefore allow the author (or the orator) to bypass elaborate explanations. As in fairy tales, therefore, or even biblical parables, case studies and exempla can require explanation (as is often the case in training contexts), but they can also do without it. In other words, rather than illustrating the theory, they permit one to transcend it.

Thomas Kuhn describes a comparable phenomenon in The Structure of Scientific Revolutions (1962/1996). Contrary to what one may think, the formation of a community and field of knowledge in the scientific domain comes less from the specification of the set of rules defining the discipline than from the "common ground" of examples that illustrate, and most often take the place of, rules. These canonical examples constitute the groundwork acquired by young scientists over the course of their training, which gives them a working knowledge without the ability to explain how it works (Kuhn $\left.1962 / 1996,43^{-51}\right)$.

Kuhn is helpful for us in comparing somatic and scientific discourses, for a particular reason: namely, the integrity of the paradigm. The structuring of somatic discourse around the case study, in its various forms, leads to a way of formulating knowledge that excludes precisely that which it claims to demonstrate, namely, "verification."The ultimate perspective of the somatic narrative, its vanishing point as it were, is always a previous somatic narrative whose inevitable starting point is the autobiographical story of the founder. Paradoxically, these accounts are most often lacking in specifically "somatic" elements: we learn very little of the central subject's experience in terms of "consciousness," of sensing. If it is often a question of transformations of posture or a function (such as breathing, digestion, general motor skills, etc.), it is always done from the point of view of the observer. And if, as in the sciences, the examples or questions asked can be applied to all fields of knowledge, then modes of explication are strictly limited to what the paradigm can provide. This is what causes-sometimes in a very comical way-the same patient to get excellent explanations for his/her problem from completely different explicative models. In one instance, a patient's scoliosis is attributed to a problem of perception; in another his/her liver is the cause; elsewhere, undeniably, it is a biomechanical problem of which his vertebral configuration is the source, etc. 


\section{The subject's belief in objects of knowledge: \\ Discursive techniques as bodily techniques}

There are therefore two main models that support the efforts to legitimate the somatic field: (I) the scientific discourse, and (2) the experiential narrative. The need to reduce these two apparently polar models to a single usage or function constitutes the most prominent paradox of somatic discourse. Thomas Hanna (1995) and Carl Ginsburg (I996) have described this paradox in terms of conflicts between objective and subjective description, questioning the compatibility of the "scientific" and objective approach to the subjective knowledge of somatics. But they did so with regard to the relationships between the sciences and somatics, and their observations missed the contradiction internal to somatic discourses.

At the core of somatics, belief determines the production of discourse. If it is received unfavorably in the other discursive world of the academy, one must question it in its own milieu, which is that of practice. As we have already seen, somatics aims to be an "alternative," even subversive, discourse with respect to medical, scientific, and social understandings of the body, which are culturally dominant. But how does somatics envision its own efficacy? Following in the footsteps of William James and Pierre Bourdieu, Basile Doganis suggests that belief is part and parcel of the somatic gesture itself. Inquiring into the forms of theorization that accompany Japanese martial arts and dances, and intrigued by the apparent contradictions that one can find in manuals concerning a single technique, Doganis suggests that the efficacy of gesture is conditional on and constituted by "faith." From the eminently pragmatic point of view of martial arts, one "must believe" in the efficacy of the action being engaged in; one must be able to change one's faith, and thus one's course of action, when the context requires it. Martial arts discourse presents contradictions when the imperative of efficacy overrides the stable criterion of truth in a given method (Doganis 2006, 237). Somatic discourses, therefore, must be read as performative discourses, situated in a precise context and targeting thereby an equally precise efficacy. In this regard, somatic discourses do not stand apart from the practices that engender them. Their value is not universal but isolated, and their validity can only be measured by the effect they produce on a given subject, in his/her encounter with a given context. Somatic discourses constitute physical techniques, just as do the practices from which they emanate. We can now conclude with this proposition: endogenous somatic discourses have a strictly performative function as techniques of the body, and their sole function is to contribute to the efficacy of somatic gesture. ${ }^{13}$

\section{Shusterman: The Temptations of Proof}

But somatics is not limited to the studio, and its recent introduction into the academic world complicates our story. The recent publication in France of Richard Shusterman's Body Consciousness: A Pbilosopby of Mindfulness and Somaesthetics (2008) heralds the unprecedented recognition of somatics as a full-fledged and autonomous theoretical discipline. ${ }^{14}$ The spotlight thrown on this book by French media, and Shusterman's presence 
at numerous colloquia and conferences on both dance and philosophy, indicate that the introduction of somatic discourse to the world of academic philosophy is a momentous event. Each chapter focuses on a particular philosopher's "somaesthetics"-Michel Foucault, Maurice Merleau-Ponty, Simone de Beauvoir, Ludwig Wittgenstein, William James, and John Dewey. Shusterman critiques, even completes, the somaesthetics of each by means of somatic discourse.

The question "Can we apply somatics to philosophy?" sums up Shusterman's project. ${ }^{15}$ His book creates an interlacing conversation between the discursive classic order of philosophy and that of endogenous somatic discourse. In extracting the latter from their original context-feeling and the experiential here and now-in order to place them in dialogue with philosophical discourse, somaesthetics obliges us to reflect on what this extraction means, and that is what I will do in the rest of this essay.

Feldenkrais and Alexander are the principal authorities Shusterman cites. As in somatic discourse properly speaking, Shusterman's theoretical argumentation takes its "proofs" from exempla: the case study narrative and the physical anecdote, which highlight embodiment. This reliance on exempla, risky as it is, extends into Shusterman's interpretation of the philosophical texts themselves, in that his critical methodology is based on each philosopher's biography and, in particular, on the unique somatic dimensions of that biography. If references to psychoanalysis are curiously absent, we are nevertheless privy to a somaanalysis of each author, in a way reminiscent of Freudian readings of art. Foucault suffers from "anhedonia," which explains his need for intense pleasures (36). Merleau-Ponty has his mother to thank for being able to live "this intersubjectivity of immanence" that he researched diligently from the beginning of his adulthood (75). As for Simone de Beauvoir, she inherited her "negativity toward the flesh" from "[her] mother's strong distaste for the physical" (79). Wittgenstein was restless and "had great difficulty in either sitting or standing still" (133), much like the chronically ill James, who "firmly believed ... that the best remedy for his chronic ailments and poor spirits should be more vigorous exercise rather than thoughtful repose" (I76). Shusterman thus raises the vast issue of how philosophical constructions are anchored in bodily experience. But, to do so, it would take a gestural, rather than psychological, analysis of the philosophical text.

The infiltration of personal narrative betrays the presence of a discursive somatic model in philosophical discourse. Telling the body's story thus functions both as warrant for the critiques Shusterman addresses to the philosophers and as warrant for his own arguments. But, just as with endogenous somatic discourses, this proof through lived experience is insufficient. The more we read through the book, and the more the philosophers become reconciled with a "healthy" physical practice, the more Shusterman's recourse to scientific discourse grows in importance. Shusterman uses the "Weber-Fechner law"16 multiple times to support the idea that mild sensations are preferable to intense sensations or efforts, and he treats it as irrefutable and universal. The general structure is that of academic philosophical discourse, but somatic discourse infiltrates the text, surreptitiously imposing two antagonistic patterns-lived experience and scientific explanation-onto the philosophical argument. The question of the body in philosophy lets itself be taken in by 
the temptation of proof, and, reciprocally, the performative function of somatic belief obtains a normative function.

\section{Good and bad gestures}

Another problem with Shusterman's book concerns the nature of somatic models, which serve as paradigms, and the tendency of these models to become ideology. The originality of Shusterman's subject is encompassed mostly in his use of these two techniques as angles from which to approach the questions the philosophers raise. As in Shusterman's earlier works, Alexander technique and the Feldenkrais Method are explicitly and amply cited in this book. The choice of these two methods is pertinent in the first place because these two men seem to represent a critical mass of respectability in an ocean of somatic studies: this is thanks to their longevity, the number of practitioners that work in their schools, and the empirical results produced from their work. But he also implicitly indicates something that could be called an aesthetic of gesture, if it did not also function as a norm at the core of the book.

Shusterman says nothing of what links the two techniques, or what distinguishes them from others. Often compared, paralleled, or put in competition with one another, the techniques of Alexander and Feldenkrais aim to reorganize an array of acquired coordinations or automatisms. As such, they both work on how gestures are initiated, and they try to deconstruct and then reorganize the gestural babitus. If they both start with concrete practices that imply movement and perception, they both also seek a reorganization of motor command; or, in the terms of Feldenkrais, these techniques work with the nervous system. They thus differ markedly from other techniques that aim, for example, for the transformation of form, strength, or the texture of tissues-training and softening techniques, manual techniques for restructuring the skeleton, (like osteopathy), or tissues (as in rolfing) —or are centered around relational or intercorporeal dimension, like Body-Mind Centering or contact improvisation.

These two methods share a common goal - the improvement of coordination - and, dependent upon that, the improvement of certain movement qualities necessary to this end. I will cite three principal movement qualities, omnipresent in Shusterman's text: The first is a slow movement that is "reversible" according to a favorite term of Feldenkrais, that is, movement that can be interrupted or reversed at any moment-a movement without momentum or impetus. The second is a mild movement that is less intense, favoring economy of effort and a maximum perception of change (sensitizing of perception is a tautology). The Weber-Fechner law is most often cited in support of these first two qualities. The third is an attention focused on the self, or awareness, which is the substratum of all somatic methods. This attention permits us to address the nonconscious or automatic aspects of ongoing movements, in order to change their organization. ${ }^{17}$ In Alexander technique, the fundamental notion of inhibition consists of "preventing" habitual motion, in order to make another one possible. Because they are instrumental to the reorganization of the gestural babitus, these three conditions constitute the constant norm of the Feldenkrais Method, the leitmotif of his teaching, and the central values of its discourse: moving very slowly and very little, and develop- 
ing an increasingly fine attention to increasingly subtle movements. Too often, it seems to me, these three conditions are interpreted as the norms of movement in general; detached from the context of the session of somatic practice, they pass for the definition of "good movement," indeed, of good living. They thus cease to appear as specific conditions that permit the acquisition or the stabilization of new coordinations, in order to crystallize as the model of "good movement." It is no longer only during the session specifically devoted to somatic practice-lying on the floor or sitting in a chair to explore the possible variants of a transfer of pressure or the direction of a look-that one must commit to slow and calm movement with one's attention focused specifically on the initiation of the movement. We also commit to it when having sex-“'A gentle grazing touch can provide more potent pleasure than a thunderous thrust" (Shusterman 2008, 37) — and in our daily life- "more enjoyable modes of breathing, sitting, lying, stretching, walking, eating, as well as the enjoyment of more specific modes of exercise" (35).

I suggest that Shusterman's book is subject to such a normative shift. The methods Shusterman favors-supported not only by reference to Alexander and Feldenkrais but also through yoga, tai-chi-chuan, or zazen-have these elements in common: they favor slowness, a feeble articulatory amplitude, a minimum of muscular effort, and, above all, an attention directed toward the self. They are all "solitary techniques," not in that one must necessarily practice them by oneself, but in that they are not dependent or organized according to attention directed toward the other or toward the group. Shusterman's text, throughout its list of "meliorative" techniques, thus illustrates an implicitly homogenous universe structured around his explicit "preferences" for Feldenkrais or Alexander. It is an imaginary, or an aesthetic prescribing a path to amelioration as a peaceful, slow, gentle, and meditative approach. Opposed to this universe of "preferable" techniques is another list, that of somatic practices that are too intense and violent, of which Foucault's sadomasochism is the epitome: "The persistent demand for extreme intensities threatens not merely to reduce that range of our felt pleasures but even to dull our affective acuity, our very capacity to feel our bodies with real clarity, precision, and power" (Shusterman 2008, 38). Thus, Shusterman comes to read Foucault as a "philosopher of the body"; he starts from the latter's research on sadomasochism and drug use and interprets them as evidence of personal "physical practices," detached from all collective and political authority and judged according to somatic norms unique to Feldenkrais:

If pleasure is so hard for Foucault, both in the sense of difficult to achieve and as narrowly directed toward the hardest, most violent intensities exemplified by S/M and strong drugs, it is tempting to see these two forms of hardness as causally connected.... If dissatisfaction with ordinary pleasures spurs the demand for more intense stimulation, then meeting that demand raises the threshold of what can be felt as satisfying, thus condemning too much of everyday experience to joyless tedium. Anhedonia's link to drug abuse (and suicide) is by now well documented, and the precise neural mechanisms of this causal nexus are currently being explored. (38) 
I hope that this passage will sufficiently highlight the risks of instituting the strategies proper to somatic practice into social norms of good movement and good sensing. The somaesthetics of Shusterman thus arranges itself according to an axiology of the more and the less, where exaggerated techniques (too much effort, feeling, speed, force, etc.) embody a modern Western civilization of violence, whereas the subtle techniques could be a pathway to improving of the self that seems to be the only path possible for collective salvation. Thus emerges an ideal of the body and of experience centered on the self, where "pleasure" can only qualify as measured pleasure, while immoderate perceptive and sensory experience is in reality marked by a "deficit": of finesse, of feeling, of democracy, etc. The dichotomies between natural and artificial, ancestral and contemporary, Eastern and Western, slow and fast, gentle and violent, conscious and "un-self-aware," imperceptibly form the environment of self-awareness, with its solid boundaries of "good" and "bad" sensation. There is an absolutely foundational principle of Feldenkrais's thought that is still strangely absent from this argument: that of alternation and the virtue of variety, which structures Feldenkrais's syntax based on contrast and which obviates any temptations of dogmatism. I certainly do not believe, however, the idea that the somaesthetic project of Shusterman is that of such a corporeal and gestural normativity. His earlier works on Feldenkrais and Alexander remove any doubts of his deep understanding of these questions. The slippage in Body Consciousness bears witness, in my opinion, to the imprint of cognition in bodily practices, marked on one hand by the dynamic of belief but also, on the other, by the concomitant dynamic of doxa.

\section{For an Epistemology of Somatic Discourses}

In extracting somatic discourses from a relationship with the techniques and experiences with which they are linked, as well as from their field of efficacy, to constitute them as autonomous theoretical systems, Shusterman poses an important implicit argument: empirical knowledge of the body and of somatic practices have something to teach philosophy, notably philosophy of the body. But this displacement causes us to question the validity of this knowledge once it becomes autonomous.

An epistemology of somatic discourses is thus necessary, according to three principle axes:

- Their modes of efficacy (as techniques of the body): It is a question of understanding what imaginary of the body subtends these discourses and thus, in this regard, which bodies are able to stand forth. This is the work undertaken many years ago by Hubert Godard, who shifted the question of scientific truth toward that of imaginary production.

- Their status of "alternative knowledge": Here there is a culturalist reading that tries to understand how somatic conceptualization is opposed to or differentiates itself from the dominant physical culture. Such is moreover the doxa unique to the somatic methods that Shusterman uses to make the principle argument of his book.

- But we have also seen how this alternative model can drift toward a particularly exclusive and homogenous norm. We must then think of somatics as a normative system and analyze its ideological construction, as I have thus far attempted to do in my analysis of Shusterman. 
Separated from their usual contexts, somatic discourses are mobilized by thoughts of the universal. They are freighted with innumerable ideologies: the natural (indeed, the animal), the transcendent (indeed, the religious), the biological difference of the sexes, and cultural hierarchies. They cover the world of their tautology, ignoring what is unfamiliar to them and creating a system of reference centered on itself. My hypothesis is the following: behind the insistence on the singularity of each corporeality, most somatic methods have as a backdrop a homogenous, universal, ahistorical, and occidental body. Furthermore, despite the interest of Feldenkrais and others in the plasticity model — the idea that most human functions are acquired and that the nervous system is in perpetual re-articulation in relation to contextual variation - an essentialist ideal of the body reasserts itself, one that brings with it illusions of the natural and organic. This essentialist body shows through in the reading of endogenous discourses, as we have already seen, and it pervades Shusterman's discourse. But it also organizes exchanges of interdisciplinary knowledge - or their absence. I will touch upon two fields of knowledge whose absence, at the heart of somatic reflection, seems to me particularly significant: on one hand, the question of the intercultural; on the other, neuroscience and its recent investigation of the body image.

\section{Cultures}

The transcultural nature of the influence of Judo on Feldenkrais, of Aikido on Contact Improvisation, and of multiple Eastern techniques and therapies on Body-Mind Centering is rarely discussed, except in the guise of a barely disguised Orientalism. The East is often seen as the antidote to the afflictions of a Western body that can be taught a better relationship to the environment, to stress, to breathing, etc. Paradoxically, then, what is borrowed from multiple cultures does not disturb the homogeneity of the body produced by somatics because the main purpose is to take care of or heal a Western body, a victim of its own culture. Thus, any confrontation with racial enmity would have to be dealt with in somaesthetic terms that do not account for otherness. Shusterman shares this point of view:

If racial and ethnic enmity resists resolution through logical means of verbal persuasion because it has a visceral basis of discomforting unfamiliarity, then as long as we do not consciously attend to these deep visceral feelings we can neither overcome them nor the enmity they generate and foster. Disciplines of somaesthetic awareness, involving a focused, systematic scanning of our bodily feelings, is first helpful in identifying these disturbing somatic sensations so that we can better control, neutralize, or overcome them. (r3o)

Here, as in relation to "Foucault's disciplinary program of S/M" (44), Shusterman transforms the strategies of efficacy used in somatics into gestural and sensory norms. In doing so, he veils the eminently political and social dimensions of racism and well as of sexuality, reducing somatics instead to one standard for individual physical sensations.

Such a use of somatic practices is not only inappropriate, it is also dangerous; it ends up replacing a political and social conscience with a "somatic" conscience that views the subject as closed and autonomous. In this era of globalization and at a time when contem- 
porary Western society is unavoidably multicultural, can we really frame the question of racism in these terms, while ignoring the cultural entailments of somatic methods? Is the somatic body so universal that it transcends this issue ${ }^{18}$ Thought to respond to culturally and historically determined ills, somatics has not conceptualized the social changes that accompanied its development; instead, it has remained fixated on the concepts of body and culture current at the time of its advent. How can somatics respond to the needs of a non-Western public, in a time of globalization and massive immigration? Is Shusterman's hypothesis that somatic techniques will help "us" to surmount our visceral fears of the unfamiliar really adequate to this context? Can somatics help us understand the unique corporality of migrant peoples and contribute to reducing their suffering? In other words, what would somatic knowledge look like when applied to issues of postcolonialism?

\section{From body schema to cyborg}

This very ideology of a universal body undermines the need of somatics to entertain a productive dialogue with current research into cognition, the brain, and processes of perception. Some research on "body schema" maintains that the body (the brain) incorporates any object it uses as an instrument or prosthesis (for example, the cane for the blind person, the skis for the skier, or the musical instrument for the musician). We know today that the brain does not differentiate between the organic body and prosthetic instruments or other regularly used instruments. In other words, the "body" only understands itself in its capacity for action, and even more for interaction with the world, mediated or not by objects or machines. The blind person's cane exists in his mind as if it were an arm. ${ }^{19}$ The same applies to any unnatural object that is integrated into the ambulatory activity of the subject. The body, then, is not the body; the body is no more natural than artificial, and there is no inherent difference between the prosthetic used by an amputee and that which modern cyborgs graft onto themselves voluntarily. Somatics cannot ignore the philosophical consequences of this research. The conclusion "we are all cyborgs" is one consequence of this research. Somatics itself is a technique of fabricating the body, the result of which is the creation of a unique cyborg, with or without prosthetic devices. In other words, one may have to think of somatic methods as queer practices, among other processes of physical or sexual transformation of transsexuals, or even the hormonal experiments of Beatriz Preciado. ${ }^{20}$

The divide between "natural soma" and "unnatural soma" is the subject of numerous other studies (Haraway 199r; Preciado 2000, 2008), but I will not dwell on that in this article. What interests me here is determining to what extent somatics' usage of contemporary scientific research is centered on the protection of an ideology, and not on the questioning of its own presuppositions. New conceptualizations of the body don't seem to inhibit somatics' belief in a natural body, or in a body that is "more natural" than another.

\section{Risking the political}

We must therefore denaturalize somatics, and this interdisciplinary detour will hopefully facilitate a renewed understanding of the pertinence of somatics. We must leave behind naive meliorism in order to resituate the complexity that is engaged in each time that something changes in the relation of a subject to its physical, symbolic, social, economic, 
and political environment. Somatics therefore does not pretend to restore a so-called natural or original body but rather contributes to the reorganization of the multiplicity and heterogeneity of that which we call the body. On these conditions alone can we then try to reflect, as does Shusterman, on their social and political potential. What conditions need to be in place in order for introspection and the recognition of physical sensation to be capable of suspending, of even interrupting, the violence of racist aggression? What somatic imaginary can counterbalance the medical imaginary that people with chronic illnesses are condemned to? What mode of continuity and what invention of the self, such that somatic methods produce them, would permit the most fragile among us to become strong? "What we are lacking is life, which is to say: resistance. Resistance is what we want. Resistance to flexibility, to this ideological norm" (Malabou 2008, 68). How does the Weber-Fechner law play itself out when one lives in the street, and one's resistance to the cold lowers one's threshold of sensitivity to the point where one loses consciousness of accidents and injuries? We must admit that most of us, somatic practitioners, researchers, or philosophers, will never know what "sensation" means for a migrant subject whose sensitive body is brutally plunged into a hostile environment whose textures, temperatures, smells, and tastes are profoundly foreign to it. Our sensations themselves are in no way exempt from ideology, exclusions, or disenfranchisement.

We have to admit that the "soma" has always been an artificial composite; that no purity, no innocence, no naturalness resides in our modern sensations, and that the "simple pleasures" of a well thought out somaesthetic culture cannot seriously exclude the most extreme physical imaginaries. We must recognize the appearance of new "techno-bodies" described by post-Foucauldian and postqueer philosophy — such as those that use prosthetics or are de-gendered, and "pharmacopolitically" modified - and become interested in the possible effects of an erudite somaesthetic consciousness on the latest cyborgs. We must admit that our models of perception and sensation have long been irrevocably directed toward bodies equipped mechanically (conveyances, machines, electronics, etc.), perceptively (technologies to improve sight and hearing at a distance), and chemically (doping and relaxing products, alimentary and hormonal complements, etc.). We must admit that the "soma" has for a long time been a cyborg-soma whose reflexive, contemplative, and respiratory practices are nothing but one technological avatar among others. We must not compare tranquility, slowness, or sensory retention to extreme sensations but rather be curious about their encounter. We must ask ourselves what an awareness or "the calm pleasures of breathing" would do to the testosterone-injected body of Beatriz Preciado, to bodies modified by plastic surgery, or to the addictive video games habits of children.

Such a program presupposes that we take the historicity of somatic practices into account and then bring about two important changes in the "theoretical" discourse produced by somatic practices. On the one hand, we need to constitute somatic practices as objects of research, in the classic sense of the term, and thus open them up to important transdisciplinary studies (historical, anthropological, cultural, etc.). On the other hand, this presupposes a different status for the contemporary implementation of these practices. This means developing, as all physical work has always done, an endogenous discourse coming from contemporary practices and freed from the norms imposed by the founders. 
Many practitioners who practice in highly precarious intercultural and special education contexts empirically develop a theory of their own practice. They know what these contemporary spheres impose as a displacement of their practice, and what contextual parameters they must take into consideration even if the original norms of their methods ignore them. In the majority of cases, their practice itself is interdisciplinary, in that they cooperate with teams variably made up of doctors, pedagogues, psychologists, and social workers. In sum, they equip these practices with a social conscience that the "founding" texts cannot provide.

In conclusion, let's return to the performative discourse from which we strayed momentarily and admit that if endogenous somatic discourses are techniques of the body, the same must be said of theoretical discourses. We must ask ourselves what body it is urgent to produce, what theoretical discourse could invent a body that is both conscious and unconscious, a body that can act and resist, a flexible body and an unshakeable body. We must ask how to value perceptive modes of low intensity, control, tranquility, and detachment, without renouncing a frenzied uncontrollable warrior body. We must inquire whether the values dear to somatics should not be reconsidered, given that they ring strangely with the overshadowing ideological phobias of the powers that be.

\section{Translated from the French by Allegra Barlow and Mark Franko}

\section{Notes}

I. The work of Georges Vigarello (2001, 2008) on the history of physical practices comes immediately to mind, as well as numerous studies of the early twentieth-century physical culture movement in Germany.

2. Somatic practices subscribe to mind-body unity and accept both objective and subjective standards of knowledge in the interpretation of experience, be it that of the practitioner, the client, or the patient. I limit the category of somatics in this article to recent Western techniques and thus distinguish them from the numerous physical practices that come from Eastern cultures, such as yoga and martial arts. Somatics borrows liberally from non-Western practices, and both attract a common public that often turns to them for answers to the same questions. My principle interest in this essay, however, is in Western somatics and its particular brand of rationality, which, it seems to me, is quite different from traditional Eastern forms, even when they are addressed to a Western public.

3. A study of the aesthetic impact of these techniques on ways of dancing and particular choreographies, especially in contemporary dance, should be undertaken, and would no doubt show how they have contributed to the construction of a singular body. In France, for example, the past fifteen years have witnessed a heightened usage of the Feldenkrais Method for dancers; more recently, we have seen a massive interest in yoga, which seems to accompany the emergence of a danced corporeality that is more postural than dynamic, more plastic than musical. Moshe Feldenkrais (1904-1984) founded the Feldenkrais Method, a technique that is practiced in collective sessions ("awareness through movement"), or in individual sessions ("functional integration"). In the former, the instructor guides the participants' movement primarily by vocal cues, whereas in the latter, s/he mostly guides by touching. It is a more educational than therapeutic method and aims to improve coordination based on a varied repertory of combinations, often on the floor, and through space at many levels.

4. For examples of the first axis, see Contact Quarterly for its pioneering role in this domain, 
or, much more recently, Nouvelles de danse in the francophone world; for the second axis, see the works of Sylvie Fortin (1996, 2002, 2005, 2008) on dancer training and his/her health, or the place given to somatic methods in journals dedicated to pedagogy or education such as Research in Dance Education or Journal on Dance Education.

5. The standing and function of the discourse of the founders within a professional discipline merits a study of its own.

6. F. Matthias Alexander (I869-I955) founded Alexander technique, which focuses on an investigation of the unconscious habits of movement in order to reorganize coordination. Head-neck coordination is fundamental, and good placement is called "primary control." Alexander technique is mostly practiced in private sessions.

7. Bonnie Bainbridge Cohen (1943-) developed Body-Mind Centering, an approach that aims to repattern physical tissues based on a structuring of the body in ten main systems: skeleton, ligaments, muscles, organs, endocrine glands, nervous system, fluids, fascia, fat, and skin. Each system can be accessed by a specific mode of touching.

8. Elsa Gindler ( $1885-196 \mathrm{I}$ ) was a teacher and founder of a practice often referred to as "gymnastics of the working man," after the title of her only extant text. She never had an official following, but she had a powerful influence on her students Ehrenfried and Selver, who went on to found their own systems. Lily Ehrenfried (1896-1995) founded Holistic Gymnastics, a "pedagogical, preventative, and therapeutic" gymnastic method. This practice uses objects such as bars, mats, and supports to promote better bodily organization in relation to gravity. Charlotte Selver ( $190 \mathrm{O}-2003$ ) founded Sensory Awareness, a method prominent in the United States that connects physical and psycho-therapeutic practices.

9. Feldenkrais maintains that the human race is singular because of the simultaneous complexity and immaturity of our nervous system at birth. Evolution therefore creates a framework that justifies a need for the somatic method-for example, the simplicity of the nervous system at birth renders developmental errors almost inevitable-and even situates the somatic method within evolution. Somatics contributes to the completion of the final step. "I believe that we are living in a historically brief transition period that heralds the emergence of the truly human man" (Feldenkrais 1972, 48).

Io. In Cohen's Sensing, Feeling, and Action (1993) each developmental movement process is illustrated by sketches showing a young child in motion alongside an animal whose stride corresponds to each phase of the child's development: the frog (amphibian) for homologous movement (arms and legs move together in the same direction); the lizard (reptile) for homo-lateral movement (arm and leg of the same side move together); the salamander (amphibian) for contra-lateral movement (opposite arm and leg move together).

II. Each method has its own singular body, and thus each method has its own references to corresponding types of science as well. Neuroscience plays a crucial role for Feldenkrais, despite the remarkable biomechanical complexity of his method that comes from his early training as a physician. Thus the "nervous system" supports the explanation of his method by himself and his followers. By contrast, the work on tissue in Cohen's Body-Mind Centering is informed by a biological imaginary (cell movement, for example).

I2. As an actor, Alexander suffered from recurrent aphonia every time he went on stage.

13. This presents the possibility of some interesting theoretical insights from the point of view of dance, which are beyond the scope of this article.

I4. Shusterman defines somaesthetics as "the critical meliorative study of one's experience and use of one's body as a locus of sensory-aesthetic appreciation (aesthesis) and creative selffashioning" (2008, 19).

I5. I am paraphrasing the title of a work by Pierre Bayard (2004), whose problematic, although far more ironic, formulation than mine-can we apply psychoanalysis to literature?-is actually not so far removed. 
I6. The Weber-Fechner law in psychophysics describes the physical intensity of stimuli in relation to the perceived sensation. This law is often cited in Feldenkrais to underline the necessity to preserve subtle sensations in low-intensity efforts.

17. It is important to distinguish nonconscious from the unconscious of psychoanalysis, which presupposes processes of repression. The nonconscious in somatics is the opposite of awareness and refers to the totality of gestural and postural habits that become automatic in the sense that they demand no reflection.

I8. Don H. Johnson relates his discovery of this intercultural question during rolfing sessions with two non-Western patients (1994, 108-12).

19. This is relevant to contemporary research into body schema (schéma corporel), which should be distinguished from body image (see Gallagher 2005).

20. Preciado's recent Testo Junkie (2008) is a kind of philosophical journal of her experience during several months of injecting male hormones (testosterone) into her body without medical supervision and without the intention to change sex. Theoretical considerations of the political, economic, and medical questions of "chemical prosthesis" are interspersed with the journal. This book demonstrates an extraprofessional awareness of somatics; attention to awareness can exist at the heart of philosophical reflection and result in corporeal constructions at some distance from those Shusterman pursues.

\section{Works Cited}

Alexander, F. Matthias. 1932. The Use of the Self: Its Conscious Direction in Relation to Diagnosis, Functioning and the Control of Reaction. New York: Dutton.

Bayard, Pierre. 2004. Peut-on appliquer la pscybanalyse à la littérature? Paris: Editions de minuit.

Bernard, Michel. 200I. "Sentir et savoir selon F.M. Alexander, ou les mirages d'une interprétation exclusivement pragmatique de l'expérience corporelle." In De la création chorégraphique, 253-61. Pantin: Centre national de la danse.

Cabiers de l'association des élèves de Dr. Ehrenfried et des praticiens en Gymnastique Holistique: Elsa Gindler I885-196I. I991. Vols. 7 and 8 (Fall).

Cohen, Bonnie Bainbridge. 1993. Sensing, Feeling, and Action: The Experiential Anatomy of BodyMind Centering. Northampton: Contact Edition.

Doganis, Basile. 2006. "La pensée du corps. Pratiques corporelles et arts gestuels japonais (arts martiaux, danses théâtres)." Ph.D. diss., University of Paris 8.

Feldenkrais, Moshe. 1972. Awareness through Movement: Health Exercises for Personal Growth. New York: HarperCollins.

-1977. The Case of Nora: Body Awareness as Healing Therapy. San Francisco: Harper and Row.

- I981. The Elusive Obvious or Basic Feldenkrais. Capitola, CA: Meta.

Fortin, Sylvie. 1996. "Léducation somatique: Nouvel ingrédient de la formation pratique en danse." Nouvelles de Danse 28: 15-30.

- 2002. "Living in Movement: Development of Somatic Practices in Different Cultures." Journal of Dance Education 2 (4).

- 2005. "Dancers' Application of the Alexander Technique." Journal of Dance Education 5 (4): $125-31$.

- 2008. Danse et santé, Du corps intime au corps social. Montreal: Quebec University Press. Fortin, Sylvie, Warvick Long, and Madeleine Lord. 2002. "Three Voices: Researching How Somatic Education Informs Contemporary Dance Technique Classes." Research in Dance Education 3 (2): 155-79.

Gallagher, Shaun. 2005. How the Body Shapes the Mind. Oxford University Press. 
Ginsburg, Carl. 1996. "Is There a Science to the Feldenkrais Magic?” Unpublished keynote address, International Feldenkrais Federation Conference, Heidelberg.

Hanna, Thomas. 1995. "What Is Somatics?" In Bone, Breath and Gesture, edited by Don H.Johnson, 339-52. Berkeley, CA: North Atlantic Books.

Haraway, Donna. I991. "A Cyborg Manifesto: Science, Technology, and Socialist-Feminism in the Late Twentieth Century." In Simians, Cyborgs and Women: The Reinvention of Nature, 149-8I. London: Routledge.

Johnson, Don H. 1994. Body, Spirit and Democracy. Berkeley: North Atlantic Books.

- 1997. Groundworks: Narratives of Embodiment. Berkeley: North Atlantic Books.

Kuhn, Thomas S. 1962/1996. The Structure of Scientific Revolutions. Chicago: University of Chicago Press.

Malabou, Catherine. 2007. Les nouveaux blessés, de Freud à la neurologie: penser les traumatismes contemporains. Paris: Bayard.

- 2008. What Should We Do with Our Brain? Translated by Sebastian Rand. New York: Fordham University Press.

Preciado, Beatriz. 200o. Manifeste contra-sexuel. Paris: Balland.

. 2008. Testo Junkie, sexe, drogue et biopolitique. Paris: Grasset.

Sacks, Oliver. 2006. The Man Who Mistook His Wife for a Hat and Other Clinical Tales. New York: Touchstone.

Shusterman, Richard. 2008. Body Consciousness: A Philosopby of Mindfulness and Somaesthetics. Cambridge: Cambridge University Press.

Vigarello, Georges. 200I. A History of Rape: Sexual Violence in France from the 16 th to the 20 th Century. Cambridge: Polity.

. 2008. Concepts of Cleanliness: Changing Attitudes in France since the Middle Ages. Cambridge University Press. 